\title{
POLÍTICAS DE FORMAÇÃO DE PROFESSORES E DOCÊNCIA NO ENSINO MÉDIO BRASILEIRO
}

\author{
TEACHER TRAINING POLICIES AND TEACHING IN BRAZILIAN HIGH SCHOOLS \\ POLÍTICAS DE FORMACIÓN DE PROFESORES Y DOCENCIA EN LA ENSEÑAN- \\ ZA MEDIA BRASILEÑA
}

\author{
Adriana e Silva Sousa \\ Professora da Universidade Estadual do Piauí (UESPI). \\ Doutoranda do Programa de Pós-graduação em Educação da Universidade Federal do Rio Grande do Norte (PPGED/UFRN).
} adrianaess.2016@gmail.com

Dante Henrique Moura Professor do Programa de Pós-graduação em Educação Profissional do Instituto Federal de Ciência e Tecnologia do Rio Grande do Norte (PPGEP/IFRN) e do Programa de Pós-graduação em Educação da Universidade Federal do Rio Grande do Norte (PPGED/UFRN).

RESUMO: O texto discute as relações entre as principais políticas de formação de professores e a precarização das condições de trabalho docente no ensino médio brasileiro, considerando o contexto de reestruturação produtiva instaurado mais fortemente no Brasil a partir da década de 1990. A construção deste texto é fruto de uma pesquisa bibliográfica e documental na qual buscamos entender quais são as principais determinações postas à formação de professores desde a aprovação da atual Lei de Diretrizes e Bases da Educação Nacional (LDB - Lei no 9.394/1996). As discussões realizadas mostram que apesar dos avanços propostos pela legislação vigente, ainda há de forma contundente a necessidade de investir esforços na concretização de políticas que integrem formação, carreira, remuneração e condições dignas de trabalho. Além disso, registra-se a permanência de diferentes tipos de organização da formação docente, assim como uma diversidade de instituições que tem contribuído para a precarização do trabalho docente. Contraditoriamente, o professor também pode se constituir em um novo tipo de trabalhador intelectualizado, potencializando a possibilidade de o professor formar-se na perspectiva contrahegemônica, dominando além dos conhecimentos exigidos pelo capital, aqueles que lhe permitam ter uma compreensão crítica do mundo e das relações sociais e de produção sob a égide do capital.

PALAVRAS-CHAVE: Formação de professores. Condições de trabalho. Ensino médio.

ABSTRACT: The text discusses the relations between the main policies of teacher training and precariousness of work conditions for teachers in Brazilian high schools, considering the context of productive restructuring most heavily installed in Brazil beginning in the 1990s. Construction of this text is the result of a bibliographical and document research in which we try to understand the main determinations placed on teacher training are since the approval of the current Law of Directives and Bases of National Education (LDB - Law $n^{\circ}$ 9.394/1996). Discussions showed that despite advances proposed by current legislation, there is still a need to invest in implementation of policies that integrate training, career, remuneration and decent working conditions. In addition, the existence of different types of teacher training organization has been registered, as well as a diversity of institutions that have contributed to the precariousness of teaching work. In contrast, the teacher can also become a new type of intellectualized worker, potentializing the possibility of the teacher training himself against the hegemonic perspective, dominating beyond the knowledge required by capital, those that allow him to have a critical understanding of the world and the social relations and production under the aegis of capital.

KEYWORDS: Teacher training. Work conditions. High school. 
RESUMEN: El texto examina las relaciones entre las principales políticas de formación de profesores y la precarización de las condiciones de trabajo docente en la enseñanza media brasileña, basándose en el contexto de reestructuración productiva establecido de forma más efectiva en Brasil a partir de la década de los noventa. La elaboración de este texto es fruto de una investigación bibliográfica y documental en la que buscamos comprender cuáles son las principales normas aplicadas a la formación de profesores desde la aprobación de la actual Ley de Directrices y Bases de la Educación Nacional (LDB - Ley $n^{\circ}$ 9.394/1996). Los planteamientos realizados señalan que pese a los avanzos propuestos por la legislación vigente, aún hay de forma contundente la necesidad de dedicarse más en la concreción de políticas que integren formación, carrera, remuneración y condiciones dignas de trabajo. Además, se nota la permanencia de diferentes tipos de organización de la formación docente, asimismo hay diversas instituciones que contribuyen con la precarización del trabajo docente. Contradictoriamente, el profesor incluso puede constituirse en un nuevo tipo de trabajador intelectualizado, potencializando la posibilidad del maestro formarse en la perspectiva contra hegemónica, dominando no solo los conocimientos exigidos por el capital, sino también los que le permitan una comprensión crítica del mundo, de las relaciones sociales y de producción bajo el amparo del capital.

PALABRAS CLAVE: Formación de profesores. Condiciones de trabajo. Enseñanza media. 


\section{1| INTRODUÇÃO}

Apesar de o ensino médio ser historicamente secundarizadopelas políticas educacionais brasileiras e só recentemente constituir-se um movimento de ampliação do acesso a essa etapa de ensino, ele possui uma importância estratégica na construção de "[...] uma base científico-técnica que nos permita romper com as amarras da dependência e subordinação externa e deixarmos de ser um 'país gigante com os pés de barro'. " (FRIGOTTO; CIAVATTA; RAMOS, 2012, p. 22). Trata-se,também, para Nosella (2015), de uma faseestratégica do sistema escolar no processo de democratização e modernização de uma nação.

Se considerarmos tais afirmações, não é por certo difícil dizer queo desvelamento das tramas consolidadas em torno e no interior do ensino médio mostra-se uma tarefa indispensável àqueles preocupados com o desenvolvimento econômico, político, social, cultural e educacional do país. Contudo, são muitas as questões que permeiam as políticas e a materialidade cotidiana do ensino médio noBrasil. Entre elas, podemos destacar a sua própria constituição identitária, as condições de seu financiamento, as possibilidades e limites de um ensino integrado à formação profissional, os desafios para a construção de um currículo voltado para uma formação integral, as exigências ditadas pelo mundo do trabalho e as problemáticas em torno da formação de professores. Dado os limites deste texto, nos deteremos neste último aspecto, tratandoda relação entre as políticas de formação docente e as condições de trabalho instituídas nas escolas de ensino médio a partir da década de 1990.

Para tratar de tal temática, temos que considerar o panorama posto para a educação brasileira a partir dos anos de 1990,o qual tem trazido inúmeras questões à formação e à atuação dos professores do ensino médio. Isso porque, a partir dessa década, se constituem no Brasil,novos cenários e direcionamentosa essaetapa de ensino que sãoresultantes de um processo de reestruturação produtiva que se desenvolve aliadoà implantação de políticas neoliberais e a um intenso processo de globalização da economia. Desde então, se estabeleceu no paísuma conjuntura socioeconômicacaracterizada por uma produção mais flexível, mesmo que ainda fortemente marcada pelo "velho"regime de produção; pelo desmonte do Estado na garantia dos direitos sociais que é feita de forma seletiva e excludente; e por uma economia mais dependente, já que as relações de produção e circulação se tornamfortemente interligadas entre os países.

Esse contexto socioeconômico repercute fortemente no mundo do trabalho eexige do processo educativo, seja ele dentro ou fora da escola,que desenvolva a formação dos trabalhadores com características diversas daquelas demandadas pelo taylorismo-fordismo. Passa a ser necessária, então,a formação de um trabalhador mais autônomo,flexível e intelectualizado, portanto, mais adaptado às exigências do novo padrão de produção e de sociedade.

Diante desse panorama, "[...] a escola vem se tornando cada vez mais 'essencial' à sociabilidade humana". (MOURA; LIMA FILHO; SILVA, 2015, p. 1059).Tal assertiva se consolida no fato de que o papel secundário que a escola ocupou em sua gênese vai, a cada avanço das relações capitalistas de produção, sendo superado e essa instituição vai assumindo mais intensamente uma função indispensávela esse modo de produção, dado que o desenvolvimento tecnológico e organizacional na forma de produzir e reproduzir o capital exige maior ampliação do acesso ao saber sistematizado. Isso porque o capital se modifica e produz novos conhecimentos, ao mesmo tempo em que é por eles produzido. Nesse sentido, podemos dizer que essa compreensão se coaduna com o entendimento de que, embora hajaespaço de açõescontra hegemônicas, "[...] na perspectiva do capital, a educação se constitui em processo permanente de disciplinamento, tendo em vista a produção e reprodução, naturalizada, da mercadoria." (KUENZER, 2011, p. 669). Essa concepção de educaçãoé, para nós, um fundamento necessário à compreensão do processo 
de trabalho desenvolvido na sociedade do capital e, portanto, na escola, e torna-se, assim, nosso primeiro ponto de ancoragem das reflexões aqui desenvolvidas.

Em síntese, é a partir do entendimentoda educação básicada classe trabalhadora enquanto importante instrumento de hegemonia e contra hegemonia que nos propomos investigar as relações entre as principais políticas de formação de professores e a precarização das condições de trabalho docente no ensino médio brasileiro, a partirdo contexto de reestruturação produtiva instaurado mais fortemente no Brasila partir da década de 1990. Para isso, assumimos como pressuposto que as novas exigências postas à formação de professores do ensino médio -assim como a consolidação das políticas de formação,a partir do novo padrão de acumulação capitalista -trouxeram regulamentações que acabam por se alinhar com um processo intensificação e precarização do trabalho docente.

No sentido de caminhar nessa compreensão, a construção deste texto é fruto de uma pesquisa bibliográfica e documental na qual buscamos entender quais são as principais determinações postas à formação de professores desde a aprovação da atual Lei de Diretrizes e Bases da Educação Nacional (LDB - Lei n 9.394/19961), procurando compreendê-las em sua relação com a concretude da ação docente, especificamente no que versa sobre suas condições em meio ao contexto de reestruturação produtiva. Para isso, consideramos, então, como segundo ponto de ancoragem, a intrínseca relação entre formação e trabalho do professor, partindo do entendimento de que "[...] a política de formação só tem sentido quando integrada à estruturação da carreira docente, a política salarial que assegure a dignidade do professor e a garantia de condições adequadas de trabalho." (KUENZER, 2011, p. 672).

As reflexões foram aqui realizadas considerando, além da Lei $n^{\circ}$ 9.394/96, a Resolução CNE/ CP no 1, de $2002^{2}$, a Lei no 13.005/2014³ e a Resolução CNE/CP n², de $2015^{4}$. As análises desse documentos foram feitas a partir de estudos já propostos a respeito: do ensino médio brasileiro, como aqueles procedidos por Frigotto (2012), Frigotto, Ciavatta e Ramos (2012), Moura (2010) e Kuenzer (2009); da formação de professores para a educação básica, como os realizados por Freitas (2014 e 2007), Moura (2014), Kuenzer (2011, 1999 e 1998) e Gatti, Barreto e André (2011); do trabalho docente, entre os quais estão as publicações feitas por Hypolito (2015) e Oliveira (2014).

A organização do estudo aqui proposto se dá em quatrotópicos, incluindo esta Introdução e as Considerações Finais, nos quais discutimos o ensino médio brasileiro, buscando compreendê-lo a partir das novas e velhas tendências postas a essa etapada educação básica no contexto da reestruturação produtiva, construindo assim, o panorama sobre o qual se evidencia a questão central aqui tratada. Além disso, abordamosas políticas de formação de professores para a educação básica e suas implicações sobre o trabalho docente, mostrando como esses aspectos parecem ainda ser tratados de forma desconexa na legislação educacional brasileira, mas, ao mesmo tempo, se inter-relacionam fortemente na concretude da ação docente.

\footnotetext{
${ }^{1}$ Estabelece as diretrizes e bases da educação nacional.

${ }^{2}$ Institui Diretrizes Curriculares Nacionais para a Formação de Professores da Educação Básica, em nível superior, curso de licenciatura, de graduação plena.

${ }^{3}$ Aprova o Plano Nacional de Educação 2014-2014.

${ }^{4}$ Define as Diretrizes Curriculares Nacionais para a formação inicial em nível superior (cursos de licenciatura, cursos de formação pedagógica para graduados e cursos de segunda licenciatura) e para a formação continuada.
} 


\section{2 | O ENSINO MÉDIO BRASILEIRO: TENDÊNCIAS E DESAFIOS}

É preciso que se reafirme que a discussão realizada sobre o ensino médio no Brasil,a partir da década de 1990,passa a considerá-lo como etapa final da educação básica por força da Lei $n^{\circ}$ 9.394/1996. Dessa forma, o ensino médio perde, do ponto de vista legal, seu caráter de intermediação entre o ensino fundamental e o ensino superior, como afirma Kuenzer (2009). Embora Nosella (2015) considere que na referida lei o ensino médio perdeu seu destaque e identidade conceitual própria,entendemos que essa inserção na educação básica coloca-o no contexto de uma regulamentação mais ampla, poiso trata juntamente à educação infantil e ao ensino fundamental, sinalizando para uma maior organicidade da estrutura, organização e funcionamento dessas etapas de ensino que se articulam para constituir a educação básica à qual todos devem ter direito,mesmo que ainda não se tenha superado a real fragmentação entre elas. Também consideramos que tal fato não destitui o ensino médio de suas especificidades,ou mesmo das características que lhe são próprias no contexto das políticas educacionais, uma vez que muitas de suas tensões permanecem e outras são criadas a partir do novo contexto socioeconômico que é posto.

Nesse sentido, o ensino médio é redefinido no contexto da legislação educacional brasileira, mas não supera questões históricas como aquela que diz respeito à dualidade entre ensino propedêutico e ensino profissionalizante; ensino público e ensino privado - problemáticasque influenciam as principais políticas e ações realizadas em torno do ensino médio no Brasil. No sentido de abordar essa questão do caráter profissionalizante ou propedêutico do ensino médio nos parece serindispensável considerar que:

[...] o acesso a esse nível de ensino e a natureza da formação por ele oferecida - acadêmica ou profissionalizante - inscrevem-se no âmbito das relações de poder típicas de uma sociedade dividida em classes sociais, às quais se atribui ou o exercício das funções intelectuais e dirigentes, ou o exercício das funções instrumentais. Ou seja, inscreve-se no âmbito da concepção de sociedade. (KUENZER, 2009, p. 26).

Tal afirmação nos indica, portanto, que as regulamentações acerca do ensino médio são decorrentes não só de um pensar pedagógico acerca da educação brasileira e de sua organização e estrutura, mas também das relações políticas, sociais e econômicas implicadas no padrão de acumulação capitalista de cada época. Não por acaso se percebe uma forte influência da dualidade entre formação propedêutica e profissionalizante nas diversas legislações que versam sobre o ensino médio no Brasilcomo forma de atender às exigências do desenvolvimento socioeconômico de cada momento histórico, influenciando nos objetivos e metas do ensino médio ao "bel prazer" das necessidades de mercado.Isso quer dizer que "[...] exige-se da escola que esta se estruture de forma dual no sentido de fortalecer o modo de produção do capital que se baseia na valorização diferenciada do trabalho intelectual e do trabalho manual, do trabalho simples e do trabalho complexo." (MOURA, 2014, p. 14).

É nesse contexto queo ensino médio foi se organizando e reorganizandoa partirde uma perspectiva dual de educação em que a formação profissional vai possuir, primeiramente, um caráter assistencialista edepois passa a assumir a função de preparar o operário para o exercício profissional (MOURA, 2014). Em ambos os casos, educa-se a classe trabalhadora para a execução de um trabalho alienado e destituído do aprendizado dos fundamentos científicos da produção. Diferentemente, a escola propedêutica, notadamente a privada, esteve historicamente voltada para a formação da classe dirigente burguesa, capaz de pensar e conduzir a produção capitalista. 
Apesar da equivalência legal entre ensino propedêutico e profissionalizante no texto da primeira LDB (Lei $n^{\circ} 4.024 / 1961$ ), a dualidade entre ambos permanece e é reafirmada pela atual LDB (Lei $n^{\circ}$ 9.394/1961), uma vez que:

Como a educação brasileira é estruturada na nova LDB em dois níveis - educação básica e
educação superior -, e a educação profissional não está em nenhum dos dois, consolida-se
a dualidade de forma bastante explícita. Dito de outra maneira, a educação profissional não
faz parte da estrutura da educação regular brasileira. É considerada como algo que vem em
paralelo ou como um apêndice e, na falta de uma denominação mais adequada, resolveu-se
tratá-la como modalidade, o que efetivamente não é correto. (MOURA, 2014, p. 71).

Ainda nessa direção de ratificação da dualidade, chamamos atenção para os efeitos do Decreto $n^{\circ} 2.208 / 1997$, por meio do qual o ensino médio volta ao seu caráter puramente propedêutico, ensejando a conclusão de que, no final da década de 1990, houve uma "[...] explicitação da dualidade entre ensino médio e educação profissional e todas as consequências que isso representa." (MOURA, 2010, p. 73).

Na perspectiva de superação dessa dualidade, nota-se quena primeira década do século XXI, houve uma sinalização nessa direção por meio do Decreto $n^{0} 5.154 / 2004$, quetrouxe a possibilidade de integração do ensino médio à educação profissional técnica de nível médio. Muito embora tenha havido essa previsão legal, a materialização desse tipo de ensino médio vem ocorrendo lentamente ao longo dos anos graças ao apoio de pesquisadores do campo, de educadores, dos movimentos sociais interessados nessa questão e de algumas iniciativas governamentais. É preciso, portanto,considerar que essa nova perspectiva para o ensino médio é permeada de desafios no sentido da construção e concretização de políticas públicas que possam garantir a integração entre formação profissional e propedêutica. Trata-se de um caminho que ainda guarda diversas implicações em seu processo de consolidação, dado a conjuntura socioeconômica em que está imerso.

Em meio a esse cenário, Moura, Lima Filho e Silva (2015) defendem que o ensino médio integrado seria um momento de "travessia" para a constituição de uma educação politécnica que supere a dicotomia entre trabalho intelectual e trabalho manual e avance na direção da formação humana integral. Assim, consideram que:

[...] ao deixarmos (a academia, outros intelectuais, a maioria da classe trabalhadora e de suas entidades representativas) de disputar politicamente uma concepção de ensino médio politécnico e de ensino médio politécnico integrado à educação profissional (para adolescentes, jovens e adultos) que se possa concretizar como travessia rumo à onilateralidade, abrimos espaço e estendemos o "tapete vermelho" para que o capital aproprie-se de bandeiras históricas do campo socialista e as ressignifique alegremente em favor de seus interesses, com financiamento público e aplausos da população. (MOURA; LIMA FILHO; SILVA, 2015, p. 1078).

Sendo assim, embora o ensino médio integrado seja tomado aqui como um caminho indispensável para a constituição de uma formação humana integral numa perspectiva contra hegemônica, é preciso considerar que o ensino médio propedêutico ainda representa a maior parte da oferta dessa etapa de ensino no Brasil, ocupando importante função na formação de jovens e adultos desse país.

Realmente, nas últimas décadas aumentou significativamente o acesso dos filhos da classe trabalhadora ao ensino médio propedêutico público. Em 1991, a matrícula total no ensino médio regular (não inclui a modalidade educação de jovens e adultos- EJA) era 3.772.698; em 2004, 
esse número chegou a 9.169.35; em 2013, foi de 8.312.8155. Cabe ressaltar que o grande esforço de ampliação da oferta de vagas no ensino médio ocorreu nas redes estaduais, onde houve um crescimento de 215,4\% entre 1991 e 2004, segundo dados do Censo Escolar dos respectivos anos.

Não obstante, juntamente com a ampliação quantitativa do acesso dos mais pobres ao ensino médio veio, não por acaso, a deterioração da escola pública, de modo que a dualidade mais marcante na atualidade não é entre ensino médio profissionalizante e ensino médio propedêutico, mas entre a oferta pública das redes estaduais e a privada. Essa última, em geral, é reducionista porque limita a finalidade do ensino médio à preparação ao prosseguimento de estudos em nível superior, negligenciando a formação omnilateral do ser humano.

Já a primeira, por absoluta falta de condições materiais concretas, em geral não consegue reproduzir o que a iniciativa privada faz nem logra formar para o mundo do trabalho, de modo que engorda as fileiras daqueles que vão atuar no trabalho simples, no subemprego. Resta a formação que integra o ensino médio e a educação profissional na rede federal de educação profissional, mas a oferta é muito pequena quando comparada com a matriz educacional brasileira, menos de $2 \%$ do total de matrículas no ensino médio brasileiro, considerando, inclusive, a EJA, segundo o Censo Escolar de 2013.

Esse quadro é caracterizado por Kuenzer (2010) como uma dualidade invertida da educação,assinalada por uma realidade em que os trabalhadores têm como alternativa mais próxima a modalidade de educação geral na esfera pública cuja qualidade é comprometida pela falta de condições materiais que viabilizem o bom funcionamento, enquanto a classe média usufrui ou diretamente da escola privada que oferece o ensino médio propedêutico de caráter academicista (preparação para acesso ao ensino superior) ou da educação tecnológica pública de qualidade. Disso resulta que aos jovens e adultos trabalhadores é ofertado um ensino médio geral em que "[...] o resultado é um arremedo de educação, que, antes de ser geral e sólida, é apenas genérica e superficial, com prejuízos irreparáveis para a classe trabalhadora. " (KUENZER, 2005, p. 864).

Por tal razão, ainda que saibamos que os desafios postos à constituição de um ensino médio integrado e à superação do dualismo estrutural seja temática sobre a qual devem se ocupar os pesquisadores interessados na constituição de uma educação voltada para a formação humanaintegral e, portanto, que caminhe na superação da sociedade regida pela produção de mercadorias, nos debruçaremos, nesse momento, nas questões postas para o ensino médio de maneira mais ampla, sem considerarmos as especificidades da constituição de um ensino integrado, entendendo que essa se trata também de uma abordagem forçosa ao avanço dessaetapa de ensino no Brasil.

Nesse sentido, depois deapontar para a dualidade histórica do ensino médio que se apresenta como parte evidente de uma sociedade dividida em classes que dita os caminhos dessa etapa de ensino no país, voltamos à nossa questão central - as políticas de formação de professores e sua relação com o trabalho docente - e propomos indagações ao ensino médio no contexto socioeconômico específico instituído a partir do padrão de acumulação toyotista. Isso porque é nesse cenário que se encontram não só as perspectivas de integração entre educação propedêutica e profissional, mas também as novas exigências formativas para o ensino médio de acordo com as perspectivas do capital que vão repercutir fortemente na formação e no trabalho docente. Então, é preciso ainda fazer as seguintes questões: quais as novas exigências feitas ao ensino médio pelo novo padrão de acumulação capitalista? Quais objetivos são postos para essa etapa de ensino a partir da década de 1990? Que organização ele tem assumido a partir das regulamentações pós LDB de 1996?

\footnotetext{
${ }^{5}$ Parte dessa diminuição é explicada pela diminuição da população de 15 a 17 anos que se inicia no país a partir da segunda metade dos anos 2000.
} 
Ao buscar entendimento para essas indagações, retomamos nosso primeiro ponto de ancoragem posto na Introduçãopara chamar atenção sobre o fato de que a partir da década de 1990, foi exigida outra proposta de educação em que se pudesse atender às novas demandas da produção de mercadorias e da sua circulação, portanto, produção e reprodução de capital. Então, o ensino médio volta-se para atender essas novas demandas do mundo do trabalho, ensejando uma formação de jovens e adultos capazes de adquirir o status da empregabilidade através da obtenção de habilidades gerais básicas ou até mesmo de um treinamento para determinada profissão.

Em meio a esse contexto, a LDB vigente estabelece que o ensino médio tenha como finalidades (Art. 35):

\footnotetext{
I - a consolidação e o aprofundamento dos conhecimentos adquiridos no ensino fundamental, possibilitando o prosseguimento de estudos;

II - a preparação básica para o trabalho e a cidadania do educando, para continuar aprendendo, de modo a ser capaz de se adaptar com flexibilidade a novas condições de ocupação ou aperfeiçoamento posteriores;

III - o aprimoramento do educando como pessoa humana, incluindo a formação ética e o desenvolvimento da autonomia intelectual e do pensamento crítico;

IV - a compreensão dos fundamentos científico-tecnológicos dos processos produtivos, relacionando a teoria com a prática, no ensino de cada disciplina. (BRASIL, 1996, s/p grifo nosso).
}

Ao analisar essas finalidades, percebemos que há uma nítida preocupação em formar o trabalhador adaptado às novas exigências do capitalismo, uma vez que as capacidades de adaptação e flexibilização, próprias do toyotismo, aparecem como importantes características da formação no ensino médio. Nesse mesmo sentido, se observarmos essa lei como um todo, perceberemos que o inciso quatro é frágil, pois a compreensão dos fundamentos científico-tecnológicos dos processos produtivos tornaria indispensável uma aproximação dos alunos ao trabalho como princípio educativo.

Esse princípio permite a compreensão do significado econômico, social, histórico, político e cultural das ciências, das letras e das artes. Compreende-se, assim, que uma prática pedagógica significativa exige uma reflexão sobre o mundo do trabalho, da cultura desse trabalho, das correlações de força existentes, dos saberes construídos a partir do trabalho e das relações sociais que se estabelecem na produção.

Essa reflexão deve constituir-se em um movimento na busca da unidade entre teoria e prática, visando a superação da divisão capital/trabalho - uma utopia necessária(MORAESet al., 2013).

Assim, o trabalho como princípio educativo não se restringe ao "aprender trabalhando" ou ao "trabalhar aprendendo". Está relacionado, principalmente, com a intencionalidade de que através da ação educativa os indivíduos/coletivos compreendam, enquanto vivenciam e constroem a própria formação, o fato de que é socialmente justo que todos trabalhem, porque é um direito subjetivo de todos, mas também é uma obrigação coletiva porque a partir da produção de todos se produz e se transforma a existência humana e, nesse sentido, não é justo que muitos trabalhem para que poucos enriqueçam cada vez mais, enquanto outros se tornam cada vez mais pobres e colocados à margem da sociedade(MORAES et al., 2013).

Desse modo, é preciso que o currículo contribua para a compreensão dos dois sentidos do trabalho como princípio educativo: o histórico e o ontológico.

O trabalho é princípio educativo em seu sentido histórico na medida em que se consideram as diversas formas e significados que esse vem assumindo nas sociedades (o trabalho servil nas sociedades feudais, o trabalho escravo e outras formas degradantes de trabalho). Isso permitirá compreender que na sociedade atual, o trabalho: 
[...] se transforma em trabalho assalariado ou fator econômico, forma específica de produção da existência humana sob o capitalismo; portanto, como categoria econômica e práxis produtiva que, baseadas em conhecimentos existentes, produzem novos conhecimentos. " (RAMOS, 2004 apud BRASIL, 2007, p. 46).

Incorporar a dimensão histórica do trabalho na formação docente significa,portanto, considerar exigências específicas para o processo educativo, que visem à participação direta dos membros da sociedade no trabalho socialmente produtivo.

O trabalho é princípio educativo em seu sentido ontológico ou ontocriativo ao ser compreendido como mediação primeira entre o homem e a natureza e, portanto, categoria central na produção da existência humana. Dessa forma, é na busca da produção da própria existência por meio do trabalho que o homem gera conhecimentos, os quais são histórica, social e culturalmente acumulados, ampliados e transformados.

Nesse sentido, a oferta do ensino puramente propedêutico, voltado apenas ao prosseguimento de estudos, se tornaria inviável ao se assumir o princípio educativo do trabalho como fundante do currículo. Entretanto, esse princípio não é assumidono texto da LDB de 1996 nem na prática da maior parte da oferta do ensino médio do país, majoritariamente propedêutico e longe do trabalho como princípio educativo.

Podemos, portanto, assinalar que as finalidades do ensino médio não podem ser desatentamente avaliadas somente em seus aspectos positivos, pois embora tenha um caráter aparentemente progressista, elas guardam contradições e alinham-se aos interesses do modo de produção do capital. Dessa forma, deixa transparecer que a adaptação dos indivíduos às exigências do mercado é importante motivação dessa etapa de ensino. Em síntese, preparar o cidadão produtivo ao capital parece ser sua grande virtude.

Nesse contexto, Kuenzer (2009, p. 42) ainda chama atenção sobre o seguinte aspecto:

[...] a efetiva democratização de um Ensino Médio que ao mesmo tempo prepare para a inserção no mundo do trabalho e para a cidadania, complementado nos níveis subsequentes por formação profissional científico-tecnológica e sócio-histórica, tal como proposto nas finalidades expressas na legislação, exige condições materiais que não estão dadas para o caso brasileiro.

Em meio à dualidade estruturale à tentativa de responder a suas novas demandas de formação da classe trabalhadora, o ensino médio tem sido organizado de diferentes maneiras. Isso porque a partir da LDB de 1996, é possível que ele assuma a forma propedêutica, mesmo que a Lei verse sobre uma preparação geral para o trabalho, e a forma integrada à educação profissional com possibilidade de habilitação para o exercício de uma profissão. No entanto, há uma complexa organização dessaetapa de ensino que permite uma maior diferenciação na oferta que vai alémda polarização entre formação propedêutica e profissionalizante.

Nesse sentido, Moura (2014)alerta para a existência de vários tipos de ensino médio, a saber: o ensino médio regular ${ }^{6}$, subdividido em propedêutico diurno, propedêutico noturno, integrado à educação profissional e Normal/Magistério; o ensino médio na modalidade EJA, subdividido em propedêutico e integrado à educação profissional. Além disso, ainda há a divisão, de cada um desses tipos, em relação à vinculação às distintas dependências administrativas: federal, estadual, municipal e privada.Disso resultam "[...] diferentes processos e concepções de formação humana e, em consequência, demandam por distintos professores com diferentes formações, tanto

${ }^{6}$ Denominação dada ao ensino médio proporcionado aos jovens que se encontram na faixa etária esperada. 


\title{
inicial como continuada. " (MOURA, 2014, p. 14).
}

Sendo assim, a construção da identidade do ensino médio como etapa final da educação básica passa a ser comprometida e abre espaço para diferentes formas de organização, tornando-se capaz de excluir e incluir os indivíduos de acordo com seu lugar na divisão social e técnica do trabalho.Desse modo, seu objetivo seria:

\begin{abstract}
[...] educar os jovens na justa medida das demandas do mercado de trabalho: para uns poucos qualificação científico-tecnológica e sócio-histórica para o exercício das funções vinculadas à gestão, à criação, à direção e aos serviços especializados. Para a grande maioria, a escolaridade suficiente para permitir o domínio dos instrumentos minimamente necessários à existência em uma sociedade de perfil científico-tecnológico, complementada por uma formação profissional de curta duração, que os capacite para exercer ocupações precarizadas em um mercado cada vez mais restrito. (KUENZER, 2009, s/p).
\end{abstract}

Outra questão que merece destaque quando discutimos as políticas para o ensino médio nas últimas décadas é o avanço no que diz respeito ao acesso a essa etapa de ensino,conforme já comentado anteriormente. Essa ampliação da oferta de vagas no ensino médio vem sendo impulsionada pela Constituição Federal de 1988, pela LDB de 1996 e, mais recentemente, pela Emenda Constitucional $(E C)$ n59/2009, que tratada educação básica obrigatória e gratuita dos 4 aos 17 anos de idade. Com relação à EC n59/2009 é importante observar que, embora represente um avanço, esse é limitado, postoque vincula odireitoà faixaetária, excluindo de sua garantia os sujeitos que não concluírem a educação básica até os 17 anos de idade (MOURA,2014).

Trata-se de um importante direito que passa a ser reconhecido e coloca-se no campo de disputa para sua concretização. Um indispensável passo para a ampliação da oferta dessa etapa de ensino, mas que precisa ser considerado a partir da necessidade de um investimento seguro em educação que atenda às necessidades daí decorrentes, como por exemplo, a falta de professores e de adequadas condições de funcionamento dasescolas públicas. É nesse sentido que Freitas (2014, p. 434) assinala que a universalização do ensino médio demandará:

[...] esforço nacional para a expansão massiva de vagas em todas as licenciaturas, de modo a formar profissionais para os novos postos de trabalho na educação básica e cobrir o déficit de professores nas várias áreas em que atuam professores sem a formação específica.

Esse quadro de escassez de docentes é uma realidade que tem se agravado com o avanço das matrículas do ensino médio, mesmo que essas tenham sido retraídas nos anos mais recentes. Para Kuenzer (2011), essa situação agrava-se mais em algumas regiões do país, assim como em relação a alguns componentes curriculares. Esse quadro parece ainda mais preocupante quando a referida autora constata que não é a simples ampliação de oferta no número de vagas de cursos de licenciaturas ou até mesmo o número de matrículas de licenciandos que concluem o curso que solucionará o problema, pois muitos licenciados não atuam como professores. Isso quer dizer que o exercício da docência não é determinado apenas pela formação, mas passa fundamentalmente pela valorização profissional que inclui não só salário e carreira, mas igualmente condições necessárias de trabalho.

Em síntese, o que percebemos é que o ensino médio brasileiro ainda carece de políticas capazes de definir seus caminhos de forma a criar uma oferta responsável, tanto no sentido da construção de sua identidade como etapa final da educação básica, como na constituição de uma oferta de funcionamento digno nas escolas públicas, sendo capaz, portanto, de proporcionar um ensino médio de qualidade para todos os jovens e adultos do país. Sendo assim,coloca-se ainda para a formação e o trabalho docente os desafios de lidar com a dualidade estrutural e com as diferentes 
diferentes formas de organização que essaetapa de ensino apresenta; de problematizar suas finalidades dentro do novo contexto socioeconômico; e de lutar pela universalização da sua oferta em condições adequadas de trabalho nas escolas públicas. É nesse âmbito que situamos a discussão que faremos no próximo tópico, compreendendo como as políticas educacionais de formação de professores têm reagido a esse cenário do ensino médio aqui exposto.

\section{3 | POLÍTICAS DE FORMAÇÃO DE PROFESSORES DO ENSINO MÉDIO E A PRECARIZA- ÇÃO DAS CONDIÇÕES DO TRABALHO DOCENTE}

Como já assinalado, o cenário de reestruturação produtiva, globalização da economia e implantação de políticas neoliberais conduz ao desenvolvimento de um projeto político e pedagógico correspondenteà nova realidade e, portanto, que tenta atender às diferentes demandas de formação, seja de trabalhadores ou de dirigentes, repercutindo nos processos pedagógicos efetivados no cotidiano escolar(KUENZER, 1998). Nesse sentido, "[...] vai nascendo um novo princípio educativo não da cabeça dos educadores, mas da prática social e produtiva com suas novas determinações." (KUENZER, 1998, s.p).

Então, diante do novo padrão de acumulação, o capital exige que o professor tenha uma formação que o torne capaz de formar trabalhadores que atendam às perspectivas postas pela produção flexível (MOURA, 2014). Sendo assim, o próprio professor é um novo trabalhador que deve atuar de forma coerente com as exigências postas para superar a crise do capital e contribuir para a consolidaçãoda nova face do capitalismo. Em síntese, podemos dizer que ascende a necessidade de uma formação de professores alinhada com o contexto decorrente da reestruturação produtiva.

É, portanto, diante dessecenário quesão propostas novas regulamentações para a formação docenteno Brasil. Essas se submetem aos interesses do capital e sinalizam para uma prática pedagógica condizente com as necessidades de formação dos novos cidadãosprodutivos que sejam mais facilmente adaptáveis ao padrão de acumulação capitalista instituído a partir da crise da década de 1970. Não por acaso, notamos no país um número expressivo de regulamentações que orientam a formação de professores, em especial os da educação básica,a partir dos anos de 1990, quando o país passa a vivenciar de modo mais intenso a produção flexível. Tal fato se dá uma vez que para além das especificidades e exigências comumente postas ao educador, aliam-se outras que são inerentes ao tempo histórico, político e econômico estabelecido a partir de então e que devem ser supridas em função de atender a necessidade de disciplinamento de uma educação voltada para a manutenção das estruturas capitalistas.

A mais notável das regulamentaçõeseducacionais da década de 1990,da qual decorreuma série de determinações acerca da formação de professores,é a LDB de 1996. Essa leitraz a exigência da formação dos professores da educação básica em nível superior, levantando a necessidade de um maior preparo para o exercício da docência. Muito embora essa demanda não seja obrigatória na educação infantil e nas séries iniciais do ensino fundamental, trata-se de um importante fundamento legal, pois além de trazer à tona a importância da formação de professores na constituição de uma educação básica pública de qualidade, abre espaço para ações governamentais no sentido de atingir tal exigência, pois estas podem ser discutidas com professores e a comunidade acadêmica através de suas instituições.

Contudo,é preciso considerar que essa regulamentação é marcada pelos princípios das políticas neoliberais e sua concretização caracteriza-se pelo recuo do Estado no que diz respeito aos custos de formação, proporcionando muitas vezes uma formação de professores em nível superior 
superior, mas compouca qualidade. Kuenzer (1998, s.p) esclarece essa questão e mostra que se delineia, a partir de então:

[...] um novo espaço para a formação de professores: os institutos superiores de educação, como alternativa-"síntese" das escolas normais e cursos de pedagogia e licenciaturas. Estes passaram a exercer o que eram as suas funções, só que de forma aligeirada e de baixo custo - formação de professores em cursos pós-médios, cursos superiores não universitários, qualificação e requalificação permanente dos docentes em exercício, tudo sob a responsabilidade das Secretarias de Estado de Educação "em articulação" com as universidades.

O que parece se tornar evidente é que a formação de professores sai dos muros da universidade, mas não como modo de ampliação de espaços de formação qualitativamente positivos, mas como meio de garantir que os professores tenham uma certificação exigida legalmente, porém não necessariamente baseada nos conhecimentosexigidos para a construção e avanço de um projeto político-pedagógico pautado por uma concepção de educação socialmente referenciada. Trata-se, muitas vezes, de uma formação aligeirada e de baixo custo, como já assinalado por Kuenzer (1998) e que, segundo essa mesma autora, contribui para um trabalho docente precarizado, dado que o menor tempo de qualificação colabora não só para os baixos salários, mas também para uma formação política e pedagógica de qualidade duvidosa, dificultando ao professor o enfrentamento de questões postas no seu cotidiano.

Também para Freitas (2007), a exigência de formação de professores da educação básica em nível superior proporcionou uma expansão de cursos de forma irresponsável e desmedida, em que "[...] as licenciaturas e a formação de professores não se constituem prioridade nos investimentos e recursos orçamentários. " (FREITAS, 2007, p. 1205).

Poderíamos dizer que seria uma formação insuficiente para atender às especificidades da ação docente tão bem destacadas por Kuenzer (1998), que são: capacidade de analisar o projeto pedagógico em curso na sociedade; participar da organização coletiva na construção de relações sociais verdadeiramente democráticas; transformar conhecimento social e historicamente produzido em saber escolar; buscar formas metodológicas adequadas; construir formas de organização e gestão dos sistemas de ensino; fazer com que no processo de produção de conhecimento se expresse o desejo coletivo da sociedade e produzir ciência pedagógica.

Nessa conjuntura, Kuenzer (2011, p. 675) aponta para a precarização da formação de professores para o ensino médio aoalertar que "[...] a obrigatoriedade da formação em licenciatura pela legislação em vigor pode estar levando a soluções meramente certificatórias, sem impacto relevante sobre a qualidade do ensino médio. "Isso porque a autora questiona a alternativa de formar professores em cursos à distância, uma escolha que tem sido comumente feita na tentativa de garantir maior eficiência com menores custos. Entendemos que essa se trata, no mínimo, de uma opção arriscada, se considerarmos a necessidade de uma formação que contemple as especificidades da ação docente, já destacadas no parágrafo anterior,e até mesmo aquelas incluídas no textoda LDB de 1996,por meio da Lei no 12.014, de 2009, que versa sobre os profissionais da educação e destaca como fundamentos:

I - a presença de sólida formação básica, que propicie o conhecimento dos fundamentos científicos e sociais de suas competências de trabalho;

II - a associação entre teorias e práticas, mediante estágios supervisionados e capacitação em serviço;

III - o aproveitamento da formação e experiências anteriores, em instituições de ensino e em outras atividades. (BRASIL, 2009, s/p). 
No sentido de estabelecer princípios, fundamentos e procedimentospara a organização de cursos de formação de professores pelas instituições de ensino superior, de forma complementar à LDB vigente, o Conselho Nacional de Educação instituiu em 2002 as Diretrizes Curriculares Nacionais para a Formação de Professores da Educação Básica através da Resolução CNE/CP no 1,de 18 de fevereiro de 2002. Nela,a formação para a docência em toda a educação básica traz as marcas dasexigências postas pelo novo modelo de acumulação flexível e considera necessário o desenvolvimento de hábitos de colaboração e de trabalho em equipe;a autoavaliação no exercício do trabalho; o gerenciamento do próprio desenvolvimento profissional; o acúmulo maior de conhecimento que engloba desde a cultura geral e profissional, passando pela dimensão cultural, social, política e econômica da educação até chegar aos conteúdos das áreas de conhecimento na área pedagógica.

Embora algumas dessas exigências possam parecer próprias da formação de professores, é preciso ter claro que elas não se pautam na constituição de um projeto que caminhe no sentido da emancipação humana. Diferentemente, procuram condicionar os professoresàs demandas de uma sociedade cada vez mais exploradora e excludenteviaprincípios meritocráticos. Portanto, são demandas da sociedade do capital que aparecem interpostaspor um discurso emancipador extremamente frágil, pois têmem seus alicerces a marca da pedagogia das competências, negando os fundamentos de uma educação mais justa, uma vez que:

[...] em termos da formação acadêmica do professor, a grande disputa está na concepção de ser humano, de trabalho e de sociedade que vai orientar a proposta curricular da formação docente, sendo que tal disputa é fruto das correlações de forças existentes não apenas no interior nas instituições formadoras, mas, principalmente, no âmbito do estado (ampliado), onde se definem a concepção e as estratégias de desenvolvimento das políticas públicas educacionais. (MOURA, 2014, p. 42).

Gatti, Barreto e André (2011) assinalam que mesmo com as regulamentações postas a partir das Diretrizes Curriculares Nacionais para a Formação de Professores e das Diretrizes Curriculares de cada curso, as licenciaturas responsáveis por formar professores especialistas - portanto os professores que atuam no ensino médio - ainda se concentramna área disciplinar específica, secundarizando a formação pedagógica, destinando menor carga horária para os conhecimentos específicos da docência. Além disso, Gatti (2010) chama atenção para a falta de articulação entre as disciplinas de formação específica e as de formação pedagógica.

Assim, podemos afirmar que essas diretrizes ainda abrem espaço para a constituição de uma formação fragmentada que implica em distanciamento das questões pedagógicas que envolvem a formação de jovens e de adultos nesse nível de ensino, possibilitandoque se pense o curso de licenciatura a partir de uma perspectiva do bacharelado, corroborando com a "fuga" dos licenciados de assumir a docência como profissão ou de considerá-la como um "seguro desemprego", como aponta Gatti (2010).

As rápidas considerações aqui feitas em torno das diretrizes de 2002 são pertinentes, uma vez que estas orientaram a formação dos professores da educação básica por mais de uma década, mas é preciso repensar a temática em questão a partir da Resolução CNE/CP no 2, de $1^{\circ}$ de julho de 2015, que revoga a resolução de 2002 e define novas diretrizes. Nela é possível notar que se tentapropor uma maior organicidade à formação dos profissionais da educação básica, procurando garantir uma base comum nacional para a formação de professores (DOURADO, 2015). Contudo, é necessário ponderar que constituir diretrizes nacionais para a educação básica é um processo permeado de tensões e disputas de diferentes setores da sociedade e é nesse sentido que devemos considerar a análise feita por Freitas (2007) acerca da formação de professores, mesmo antes da aprovação dessa última resolução. Essa autora assinala que: 
A necessidade de uma política global de formação e valorização dos profissionais da educação que contemple de forma articulada eprioritária a formação inicial, formação continuada e condiçõesde trabalho, salários e carreira, com a concepção sócio-histórica do educadora orientá-la, faz parte das utopias e do ideário de todos os educadorese das lutas pela educação pública nos últimos 30 anos. (FREITAS, 2007, p.1204).

Se analisarmos o conteúdo das diretrizes, perceberemos que há uma intencionalidade no discurso muito próxima dessa perspectiva que Freitas (2007) destaca ser o caminho perseguido pelos educadores. Isso porque essa resolução, diferentemente da anterior, incorpora a proposta de uma formação de professores articulada com as políticas de valorização, agregando os ganhos da Lei do Piso e estabelece que:

A valorização do magistério e dos demais profissionais da educação deve ser entendida como uma dimensão constitutiva e constituinte de sua formação inicial e continuada, incluindo, entre outros, a garantia de construção, definição coletiva e aprovação de planos de carreira e salário, com condições que assegurem jornada de trabalho com dedicação exclusiva ou tempo integral a ser cumprida em um único estabelecimento de ensino e destinação de $1 / 3$ (um terço) da carga horária de trabalho a outras atividades pedagógicas inerentes ao exercício do magistério [...]. (BRASIL, 2015, p. 15).

Contudo, Freitas (2007) é mais radical em suas análises sobre as políticas de formação de professores e considera que uma proposta como a exigida pelos professores"[...] não se materializa no seio de uma sociedade marcada pela desigualdade e pela exclusão próprias do capitalismo." (FREITAS, 2007,p. 1204). Nesse sentido, entendemos que a aprovação das diretrizes é parte integrante do processo de valorização da formação e do trabalho docente, mas sua concretização entra em um campo de disputa no seio da práxis política que se mostra muito complexa. Portanto, mesmo que possamos apontar para suas conquistas no âmbito da legislação, não podemos romantizar essa proposta. Ao contrário, devemos tratá-la a partir da realidade que marca a formação e o trabalho docente e as contradições que lhe são postas.

Por conseguinte, não podemos deixar de notar que nas diretrizes de 2015 ainda permanecem as possibilidades de formação pedagógica de modo complementar ao bacharelado e de formação de professores em cursos à distância. Tais ofertas fragilizam, em alguma medida, a formação docente, uma vez que a concretização de tais cursos acontece, na maior parte das vezes, com condições precárias e de modo aligeirado de forma a adaptar-se às situações em que se encontram os cursistas, muitas vezes professores, que não dispõem de tempo nem de condições adequadas para investir em uma formação sólida e de qualidade.

O Plano Nacional de Educação2014-2024 (PNE) trata da formação docente de forma direta em duas metas (15 e 16). No entanto, Hypolito (2015) chama atenção para o fato de que a temática da formação de professores é mencionada no novo PNE em várias metas, aparecendo tanto como meta principal, como na forma de estratégia. Essa insistência, para o autor, está ligada à melhoria do ensino e se revela em uma série de exigências de formação específica para atender a diversidade presente na educação brasileira. Para ele, isso revela que as políticas de formação de professores concentram-se na formação continuada de modo a atender especificidades e grupos diferentes e afasta a formação da universidade, propondo, muitas vezes, uma formação mais voltada para o ensino e mais pragmática.

A meta 15 do PNE trata especificadamente da formação de professores propõe que "[...] todos os professores e as professoras da educação básica possuam formação específica de nível superior, obtida em curso de licenciatura na área de conhecimento em que atuam." (BRASIL, 2014, p. 78). Essa meta retoma, portanto, um objetivo presente na LDB de 1996,evidenciando que as políticas 
de formação de professores ainda têm se apresentado de forma ineficiente. Além disso, propõe estratégias também coerentes com essa lei que traz sérios riscos à sua concretização. Entre elas, podemos destacar o incentivo ao financiamento estudantil e a implantação de cursos e programas especiais para formação de professores em efetivo exercício. Quanto a esse primeiro aspecto, Freitas (2014) destaca que a expansão dos cursos superiores tem ocorrido fortemente a partir das instituições privadas "[...] onde a pesquisa não constitui atividade obrigatória e apenas partereduzida dos professores se insere na carreira docente" (FREITAS, 2014, p.431). Tal fato implica não só o risco de não alcançar a meta, mas também alcançá-la de forma capenga, comprometendo a valorização salarial e da carreira docente.

No que se refere à implementação de cursos e programas especiais para formação de professores em efetivo exercício, podemos dizer que a experiência ao longo dos anos tem se mostrado, no mínimo, pouco adequada, pois com frequência são propostos cursos aligeirados e de baixa qualidade acadêmica. Além disso, a realidade mais comum é o acúmulo das atividades de formação com as atividades de trabalho pelos professores, comprometendo a qualidade de ambas as tarefas.

A meta 16 do PNE propõe:

[...] formar, em nível de pós-graduação, 50\% (cinquenta por cento) dos professores da educação básica, até o último ano de vigência deste PNE, e garantir a todos(as) os(as) profissionais da educação básica formação continuada em sua área de atuação, considerando as necessidades, demandas e contextualizações dos sistemas de ensino. (BRASIL, 2014, p. 80).

Entre as estratégias para o alcance dessa meta podemos destacar: a oferta de cursos de pós-graduação por parte das instituições públicas de educação superior;consolidação das políticas de formação de professores; ampliação de acesso a obras didáticas, paradidáticas, literárias e dicionários; ampliação da oferta de bolsas de estudos para pós-graduação. Acerca dessas e das outras três estratégias que são propostas para alcançar essa meta da formação continuada, é preciso que se chame atenção para a necessidade de se pensar uma pós-graduação comprometida com a melhoria da educação pública e não apenas com a certificação dos professores de forma a melhor inseri-los nos planos de carreira.

Ainda para alcançar essa meta, Freitas (2014) assinala a necessidade de a pós-graduação assumir novas responsabilidades na formação dos profissionais do magistério da educação básica no sentido da construção de

[...] uma política para a formação dos formadores de profissionais do magistério da educação básica - expandindo a concepção de formação do docente universitário como exclusivamente de pesquisador - para a compreensão de formação de profissionais formadores do magistério da educação básica. (FREITAS, 2014, p. 436).

De modo geral, ainda é preciso considerar que a partir da década de 1990 impõe-se uma maior necessidade de que o professor participe de um conjunto de atividades antes fora de sua responsabilidade, assumindo, portanto, as características da flexibilidade e da polivalência posta para os trabalhadores no processo de reestruturação produtiva. Para isso, as regulamentações acerca da formação se voltam para atender essas necessidades, incluindo disciplinas e atividades referentes, por exemplo, à participação dos professores na gestão e no apoio às propostas que envolvam a escola e a comunidade. Mesmo percebendo que essas podem de alguma forma contribuir com o processo de ensino-aprendizagem, Saviani (2007, p. 448) nos alerta para o seguinte fato: 


\begin{abstract}
Claro que, se o professor fosse bem remunerado no âmbito de uma carreira docente que Ihe garantisse jornada integral numa única escola, ele poderia exercer, sem problemas, as mencionadas funções. Mas, trabalhando em várias escolas de comunidades diferentes, como pode ele, além de ministrar grande número de aulas para garantir uma remuneração minimamente satisfatória, participar da elaboração do projeto pedagógico dessas várias escolas, de sua gestão e, além disso, da vida dessas diferentes comunidades?
\end{abstract}

Entendemos, por conseguinte, que essas tarefas, embora façam parte da atividade docente, na prática, intensificam o trabalho do professor, pois a ele não é garantido o tempo necessário à participação da elaboração da proposta pedagógica da escola, uma vez que isso exigiria mais do que a participação nas reuniões de gestão, como comumente é feito. Igualmente, colaborar com a articulação entre a família e a escola demanda muito mais do que reuniões isoladas de pais. $A$ nosso ver, essas exigências postas ao trabalho do professor demandam condições para estudar, pesquisar e sistematizar conhecimentos no sentido fazê-lo um profissional que participe das decisões e do planejamento da estrutura, funcionamento e organização da escola. Além disso, requerer do professor que assuma essas tarefas resulta em sobrecarregaque não engrandece seu trabalho cotidiano dentro e fora da escola. Mesmo se considerarmos a lei $n^{\circ} 11.738 / 2008$, que institui o piso salarial profissional nacional para os profissionais do magistério público da educação básica, notaremos que a regulamentação em termos de tempo de estudo e pesquisa ainda é insuficiente às exigências postas à prática pedagógica. Isso porque ao professor é garantido somente $1 / 3$ de sua carga horária para as atividades que não exigem interação direta com os alunos.

Além do que já foi discutido, é preciso destacar que

[...] ao diagnosticar que o problema [da educação]está na docência e na sua má formação, as políticas conserาvadoras das últimas quatro décadas são míopes e não querem enxergar que é preciso um investimento imenso para melhorar a infraestrutura e condições de trabalho nas redes públicas de ensino. (HYPOLITO, 2015, p. 530).

Tal fato deixa mais uma vez evidente a falta de articulação entre a formação de professores e a condições de trabalho docente, o que pode até mesmo invalidar os esforços feitos em torno do preparo do professor para a profissão, pois sem materialidade necessária ao contexto escolar, inviabiliza-se qualquer tentativa promissora de uma ação docente expressiva.

Nesse contexto, a conclusão de Kuenzer (2011, p. 675),mesmo antes da aprovação do novo PNE e das Diretrizes de formação de professores de 2015, ainda parece pertinente, pois a autora assinala que:

\footnotetext{
A breve análise dos dados, das políticas e das diretrizes aponta para a necessidade de efetivo investimento em políticas que integrem formação, carreira, remuneração e condições dignas de trabalho, para enfrentar uma histórica realidade de escassez, inadequação e desprofissionalização, com seus severos impactos sobre a qualidade do ensino médio, cujas matrículas decrescem a cada ano, assim como não melhoram os indicadores de permanência e de sucesso.
}

Destacamos, ainda, que se fala constantemente na relação teoria e prática, mas pouco se fala da relação entre formação e as condições de trabalho. Nesse sentido, parece-nos claro que as políticas de aligeiramento da formação de professores e a desconsideração ao contexto em que essas políticas estão inseridas ainda é uma constante nas regulamentações aqui analisadas, mesmo que tenham apontado para avanços em torno dessa problemática. Trata-se, para nós, de uma tendência que se estabeleceu a partir da década de 1990, mas que persiste mesmo nas políticas educacionais mais atuais. 
Acreditamos, por fim, que é nesse contexto de reestruturação produtiva, o qual leva a essa reestruturação das escolas, que se consolidam importantes transformações no trabalho do professor, conduzindo a uma realidade de precariedade, pois o trabalhador docente está imerso nas relações capitalistas de produção e, portanto, não escapa das suas determinações.

\section{5 | CONSIDERAÇÕES FINAIS}

A análise sobre as relações entre as políticas de formação de professores e a precarização do trabalho docente nos leva a considerar que apesar dos avanços propostos pela legislação vigente, ainda há de forma contundente a necessidade de investir esforços na concretização de políticas que integrem formação, carreira, remuneração e condições dignas de trabalho.

Além disso, foi possível notar que essa desarticulação propõe diferentes tipos de organização da formação docente, tanto inicial como continuada, que corrobora com a precarização do trabalho do professor, tendo em vista que formações aligeiradas e feitas à distância, principalmente na esfera privada, ainda têm seu acento nas regulamentações vigentes.

Da mesma forma, a diversidade de instituições formativas não tem contribuído de forma sólida para a valorização do trabalho docente, pois transforma a pesquisa e a extensão em atividades opcionais e raramente escolhidas entres a faculdades e centros de ensino universitário, que têm no ensino sua principal, senão única, atividade formativa. Nesse contexto, torna-se difícil lidar com os novos e velhos desafios postos para o ensino médio, como, por exemplo, a dualidade estrutural, a diversidade de oferta e a expansão das matrículas.

Portanto, entendemos que o desafio da formação e valorização dos professores da educação básica passa pela necessidade de asinstituições formadoras assumirem a tarefa de formar os professores, dando a esta tarefa a importância social que possui.

Não se pode deixar de notar que a legislação aqui analisada contribui para a formação de novo professor agora alinhado com as exigências do padrão de acumulação toyotista em que a flexibilização, a adaptação e a polivalência ocupam lugar importante. Como afirma Kuenzer (2009, p. 57), "[...] um trabalhador de novo tipo, que tenha mais conhecimentos, saiba comunicar-se adequadamente, trabalhe em equipe, avalie seu próprio trabalho, adapte-se a situações novas, crie soluções originais e, de quebra, seja capaz de educar-se permanentemente."

Entretanto, contraditoriamente, essa tendência à substituição da fragmentação taylorista-fordista por procedimentos mais ampliados e intelectualizados e que demandam conhecimento da totalidade do trabalho, e não mais apenas de uma parte; que também amplia as possibilidades de participação, de decisão e de controle do próprio trabalho, representa certo risco para o capital, pois quanto mais intelectualizado for o trabalhador, mais difícil será para o capital separá-lo do conteúdo do seu trabalho. Dessa maneira, para o capital conseguir alcançar seus objetivos de reprodução ampliada necessita cada vez mais da adesão desse novo trabalhador(KUENZER, 2011).

O capital desenvolve, então, formas de cooptação do trabalhador por meio das quais ele próprio se auto explora. Como exemplos emblemáticos podemos citar os programas de qualidade total, os círculos de controle de qualidade, a participação nos lucros da empresa, entre outras estratégias por meio das quais o capital busca conquistar a adesão dos trabalhadores à ideologia da empresa, visando o aumento da produtividade e a ampliação da mais valia, oferecendo em troca, ao trabalhador, pequenas recompensas. Nessa direção, os trabalhadores deixam de ser empregados e passam a ser denominados de colaboradores engajados com o projeto da empresa, seus parceiros. Essa é a estratégia do capital. 
Não obstante, de forma contraditória, reafirma-se que essa intelectualização do trabalhador é um risco para o capital, pois fere os princípios básicos da denominada administração ou gerência científica, base do taylorismo-fordismo. Consequentemente, é uma possibilidade para a luta contrahegemônica, inclusive para o trabalhador docente.

Dessa forma, por um lado, o docente é objeto dessa mudança e, em decorrência, o capital exige para esse profissional uma formação que lhe permita formar o trabalhador solicitadopelo padrão de acumulação flexível, exigindo também do professor certo grau de adesão ao projeto do capital. Por outro lado, nesse processo, o professor também pode se constituir em um novo tipo de trabalhador intelectualizado. Isso associado ao fato de que o trabalho docente é de natureza imaterial - situação em que é difícil para o capital separar o trabalhador do conteúdo do seu trabalho -, potencializa a possibilidade de o professor formar-se na perspectiva contrahegemônica, dominando além dos conhecimentos exigidos pelo capital, aqueles que lhe permitam ter uma compreensão crítica do mundo e das relações sociais e de produção sob a égide do capital.

Desse modo, poderá contribuir para a formação do trabalhador de novo tipo que também vá além das exigências do capital, que tenha a capacidade de compreender e de analisar criticamente as suas estratégias de cooptação, resistindo e contrapondo-se a elas, tendo assim a possibilidade de constituir-se como sujeito desse processo.

Enfim, compreendemos que em termos da formação acadêmica do professor, a grande disputa está na concepção de ser humano, de trabalho e de sociedade que orienta a proposta curricular da formação docente, sendo que tais concepções decorrem das correlações de forças existentes não apenas no interior nas instituições formadoras, mas principalmente no âmbito do estado, onde se definem as políticas públicas educacionais e suas estratégias de desenvolvimento.

Assim, o espaço que cabe à perspectiva crítica é o da contra hegemonia, posto que, embora haja alguma disputa na tomada de decisões,predomina o pragmatismo que submete a lógica educacional aos interesses imediatos do capital, reduzindo a formação humana à instrumentalidade para o mercado de trabalho, em detrimento de uma formação integral.

Finalmente, é necessário que as últimas regulamentações aprovadas e que apontam para uma maior aproximação entre a formação e a valorização dos professores sejam discutidas no âmbito das instituições que formam os formadores e que, dessa forma, sirvam de instrumento para a disputa por melhores condições de trabalho e de formação docente. 


\section{Referências}

BRASIL. Ministério da Educação.Lei n 9.394, de 20 de dezembro de 1996. Estabelece as diretrizes e bases da educação nacional. Diário Oficial [da] República Federativa do Brasil, Poder Executivo, Brasília, DF, 23 dez. 1996. Seção 1, p. 27833. Disponível em: <http://www. planalto.gov.br/ccivil_03/leis/L9394.htm>. Acesso em: 23 fev. 2016.

Conselho Nacional de Educação. Resolução $\overline{C N E} / \bar{C} \mathrm{n}^{\circ} 1$, de 18 de fevereiro de 2002. Institui Diretrizes Curriculares Nacionais para a Formação de Professores da Educação Básica, em nível superior, curso de licenciatura, de graduação plena. Diário Oficial [da] República Federativa do Brasil, Brasília, DF, 9 abr. 2002. Seção 1, p. 31. Disponível em:<http://portal.mec.gov.br/ seesp/arquivos/pdf/res1_2.pdf>. Acesso em: 23 fev. 2016.

. Ministério da Educação. Educação profissional técnica de nível médio integrada ao ensino médio: documento base. Brasília, DF, 2007.Disponível em <http:// portal.mec.gov.br/setec/arquivos/pdf/documento_base. pdf >. Acesso 20 dez. 2007.

Lei no 11.738 , de 16 de julho de 2008. Institui o Piso Salarial Profissional Nacional para os profissionais do magistério público da educação básica. Diário Oficial [da] República Federativa do Brasil, Poder Executivo, Brasília, DF, 17 jul. 2008. Disponível em: http:// www.planalto.gov.br/ccivil_03/_ato2007-2010/2008/lei/ I11738.htm.Acesso em: 23 fev. 2016.

. Lei $\mathrm{n}^{\circ} 12.014$, de 6 de agosto de 2009. Altera o art. 61 da Lei 9.394, de 20 de dezembro de 1996, com a finalidade de discriminar as categorias de trabalhadores que se devem considerar profissionais da educação. Diário Oficial [da] República Federativa do Brasil, Poder Executivo, Brasília, DF, 7 ago. 2009. Disponível em: http://www.planalto.gov.br/ccivil_03/_ato20072010/2009/lei//12014.htm. Acesso em: 23 fev. 2016.

Lei $n^{\circ} 13.005$, de 25 de junho de 2014. Aprova o Plano Nacional de Educação e dá outras providências. Diário Oficial [da] República Federativa do Brasil, Poder Executivo, Brasília, DF, 26 jun. 2014. Edição extra. Disponível em: <http://www.planalto.gov.br/ccivil_03/_ ato2011-2014/2014/lei//13005.htm>. Acesso em: $\overline{6}$ jan. 2016.
Conselho Nacional de Educação. Resolução $\overline{\mathrm{CNE}} / \overline{\mathrm{CP}}$ no 2 , de $1^{\circ}$ de julho de 2015. Define as Diretrizes Curriculares Nacionais para a formação inicial em nível superior (cursos de licenciatura, cursos de formação pedagógica para graduados e cursos de segunda licenciatura) e para formação continuada. Diário Oficial [da] República Federativa do Brasil, Brasília, DF, 2 jul. 2015. Seção 1. p. 8-12. Disponível em: $<$ http://portal.mec.gov.br/index.php?option=com_docman\&view $=$ download\&alias $=17625$ - parecer - cne $-c p-$ 2-2015-aprovado-9-junho-2015\&category_slug=junho-2015-pdf\&Itemid=30192>. Acesso em: 23 fev. 2016.

DOURADO, Luiz Fernandes. Diretrizes Curriculares Nacionais para a formação inicial e continuada dos profissionais do magistério da educação básica: concepções e desafios. Educação e Sociedade, Campinas, v.36, n. 131, p. 299-324, abr.-jun. 2015. Disponível em: http://www.scielo.br/pdf/es/v36n131/1678-4626es-36-131-00299.pdf . Acesso em: 17 mar. 2016.

FREITAS, Helena Costa Lopes de.A (nova) política de formação de professores: a prioridade postergada. Educação e Sociedade, Campinas, v. 28 , n. 100 , p. 12031230, out.2007. Disponível em: <http://www.scielo.br/ pdf/es/v28n100/a2628100>. Acesso em: 17 fev. 2016.

PNE e formação de professores: contradições e desafios. Retratos da Escola, Brasília, v. 8, n. 15, p. 427-446, jul./dez. 2014. Disponível em: <http://www. esforce.org.br/index.php/semestral/article/view/451>. Acesso em: 18 mar. 2016.

FRIGOTTO, Gaudêncio;CIAVATTA, Maria; RAMOS, Marise. A gênese do decreto $n^{\circ}$ 5.154/2004: um debate no contexto controverso da democracia restrita. In: FRIGOTTO, Gaudêncio;CIAVATTA, Maria; RAMOS, Marise (Orgs.). Ensino médio integrado: concepções e contradições. 3. ed. São Paulo: Cortez, 2012. p. 21-56.

FRIGOTTO, Gaudêncio. Concepções e mudanças no mundo do trabalho e o ensino médio. In: FRIGOTTO, Gaudêncio; CIAVATTA, Maria; RAMOS, Marise (Orgs.). Ensino médio integrado: concepções e contradições. 3. ed. São Paulo: Cortez, 2012. p. 57-82.

GATTI, Bernadete Angelina. Formação de professores no Brasil: características e problemas. Educação e Sociedade, Campinas, v. 31 , n. 113 , p. $1355-1379$, out.dez. 2010. Disponível em: http://www.scielo.br/pdf/es/ v31n113/16.pdf. Acesso em: 17 mar. 2016.

GATTI, Bernadete Angelina; BARRETO, Elba Siqueira de Sá; ANDRÉ, Marli Eliza Dalmazo de Afonso. Políticas docentes no Brasil: um estado da arte. Brasília, DF: UNESCO, 2011. 
HYPOLITO, Álvaro Luiz M. Trabalho docente e o novo Plano Nacional de Educação: valorização, formação e condições de trabalho. Cadernos Cedes, Campinas, v.35, n. 97, p. 517-534, set.-dez. 2015. Disponível em: http://www.scielo.br/pdf/ccedes/v35n97/1678-7110ccedes-35-97-00517.pdf . Acesso em: 15 mar. 2016.

KUENZER, Acácia Zeneida. A formação de educadores no contexto das mudanças no mundo do trabalho: Novos desafios para as faculdades de educação. Educação e Sociedade, Campinas, v. 63, n. 19, p. 105-125, ago. 1998. Disponível em: http://www.scielo.br/scielo.php?pi d=S0101-73301998000200007\&script=sci_abstract\&tlng=pt. Acesso em:15 mar. 2016.

As políticas de formação: a constituição da identidade do professor sobrante. Educação e Sociedade, Campinas, n. 68, p. 163-183, dez. 1999. Disponível em: <http://www.scielo.br/pdf/es/v20n68/a09v2068. pdf>. Acesso em: 19 jan. 2016.

(Org.). Ensino médio: construindo uma proposta para os que vivem do trabalho. 6. ed. São Paulo: Cortez, 2009.

O ensino médio no Plano Nacional de Educação 2011-2020: superando a década perdida? Educação e Sociedade, Campinas, v. 31, n. 112, p. 851-873, jul./set. 2010. Disponível em: <http://www.scielo.br/pdf/ es/v31n112/11.pdf>.Acesso em: 19 jan. 2016.

A formação de professores para o ensino médio: velhos problemas, novos desafios. Educação e Sociedade, Campinas, v. 32, n. 116, p. 667-688, jul./ set. 2011. Disponível em: <http://www.scielo.br/pdf/es/ v32n116/a04v32n116.pdf>. Acesso em: 19 jan. 2016.

MORAES, C. S. V. et al. Formação de professores do ensino médio: ensino médio e formação humana integral. Curitiba: UFPR/Setor de Educação, 2013. v. 1.
MOURA, Dante Henrique. Ensino médio e educação profissional: dualidade histórica e possibilidades de integração. In: MOLL, Jaqueline et al. Educação profissional e tecnológica no Brasil contemporâneo: desafios, tensões e possibilidades. Porto Alegre: Artmed, 2010. p. 58-79.

Trabalho e formação docente na educação profissional. Curitiba: Instituto Federal do Paraná, 2014. (Coleção Formação Pedagógica, 3). Disponível em: <http://portal.ifrn.edu.br/pesquisa/editora/livros-para-download/trabalho-e-formacao-docente-na-educacao-profissional-dante-moura/at_download/arquivo>. Acesso em: 13 nov. 2015.

; LIMA FILHO, Domingos Leite; SILVA, Mônica Ribeiro. Politecnia e formação integrada: confrontos conceituais, projetos políticos e contradições históricas da educação brasileira. Revista Brasileira de Educação, v. 20, n. 63, p. 1057-1080, out/dez. 2015. Disponível em: $<$ http://www.scielo.br/pdf/rbedu/v20n63/1413-2478-rbedu-20-63-1057.pdf>. Acesso em: 19 jan. 2016.

NOSELLA, Paolo. Ensino médio: unitário ou multiforme? Revista Brasileira de Educação, v. 20, n. 60, p. 121-142, jan./mar. 2015. Disponível em: <http://www.scielo.br/ pdf/rbedu/v20n60/1413-2478-rbedu-20-60-0121. pdf>. Acesso em: 19 fev. 2016.

OLIVEIRA, Dalila Andrade de. Os docentes no Plano Nacional de Educação. Retratos da Escola, Brasília, v. 8 , n. 15 , p. 447-461, jul./dez. 2014. Disponível em: <http://www.esforce.org.br/index.php/semestral/article/ view/452/583>. Acesso em: 18 mar. 2016.

SAVIANI, Dermeval. História das ideias pedagógicas no Brasil. Campinas: Autores Associados, 2007. 